\title{
The Development Path of Evolution, Strategic Vision and Implementation Steps of Qinhuangdao Ocean
}

\author{
Ming LIU ${ }^{1, a,{ }^{*}}$ \\ ${ }^{1}$ School of Environmental Management College of China, No. 73 in hebei street, HaiGang District, \\ Qinhuangdao, hebei province. \\ ayinfan1015@163.com \\ ${ }^{*}$ Corresponding author
}

Key words: marine economy; Development path; Strategic positioning

\begin{abstract}
Qinhuangdao is one of the first open coastal cities in China, however, over the years, the economic development of Qinhuangdao has stayed in the "economic downturn" of China's coastal zone .Therefore,it's important to comb Qinhuangdao ocean development path of evolution and proposes the strategic positioning .Based on the sprofound analysis of Qinhuangdao ocean development path of evolution, Qinhuangdao ocean development strategy is repositioned and the implementation steps are proposesd.
\end{abstract}

\section{Introduction}

Qinhuangdao is one of the first open coastal cities in China, however, over the years, the economic development of Qinhuangdao has stayed in the "economic downturn" of China's coastal zone .In the year of 2011, the total output value of the marine economy of Hebei province is 141.1 billion, has a large gap with the advanced provinces such as Guangdon, Shanghai and Tianjin. As the mainstay of Qinhuangdao coastal areas, Qinhuangdao is lack of driving force of the whole city's economic development, the marine economy development lags behind and fails to give full play to the advantages of the coastal area.Visible, the strategic orientation of ocean is very important to the coastal city[1].

\section{The strategic positioning of Qinhuangdao ocean development}

Qinhuangdao is located in the coast of the Bohai sea, is the center of the Bohai economic circle and key nodes of Bohai sea "gold necklace". Relying on resource advantage, coastal features, shallow water resource advantages of Qinhuangdao port and combining with the requirements of the overall layout of the marine economy of Hebei, the blue economic construction of Qinhuangdao will become a national ecological economic demonstration area, finally create a strong city of economy development relying on marine resources. The specific location are:new logistics center of International commodity; High-tech industries demonstration zone of marine economy; the biggest seashore leisure base, the international first-class eco-tourism health resort; the national marine ecological civilization demonstration area and the optimal coastal livable place.

\section{The implementation steps of Qinhuangdao marine economic development}

Construct the comprehensive transportation system, and promote the service industry development

Qinhuangdao speeds up to implement the plan of "move the west port to the east", perfects the construction of port, railway, highway and airport, strives to improve the road traffic network 
extending in all directions. Taking the opportunity of cooperation with Dalian Commodity Exchange, a commodity electronic trading platform will be established, as well as the third party electronic payment platform enterprise. Qinhuangdao take the advantage of spot goods and futures goods markets to construct coal futures trading and strengthen the coal industry. There will be a large warehouse logistics support system, bulk commodity exchange, port cargo distribution center, commodities trading and price discovery center, trade operation and information hub and International exhibitions and International procurement center.

\section{The space integration and regional layout optimization of marine and ocean side industry}

- Haigang district relies on Qinhuangdao port, mainly depends on the port logistics, land logistics and airport logistics, to speed up the implementation of the "move the west port to the east" project, optimize the layout of the coastline, perfect the port function, promote the harbour city interaction, create an International commodity distribution base of coastal port logistics.

- Shanhaiguan, Beidaihe, New Beidaihe districts focus on the modern tourism to develop of cultural creative industry of leisure tourism and seaside recuperate, build high-end tourism zone, promote coastal tourism extend from the coast to the sea. In the key regional of environmental regulation and comprehensive development, marine ecological civilization demonstration area of "new east" will be created.

Economic-technological Development Area of Qinhuangdao is based on port-vicinity industry clusters, mainly develop modern logistics, advanced equipment manufacturing, new energy, new materials and electronic information industries baked on the port and ship heavy industry to build a high-end manufacturing base. By speed up the development of advanced manufacturing industry, the advantage industry of the coastal tourism, the construction of marine scientific research and industrialization base, cultivate strong port logistics, ocean shipping and engineering equipment manufacturing, Qinhuangdao will become a high-tech industries demonstration zone of marine economy.

Coastal areas emphasis on aquaculture, recreational fishery, speed up the development of shallow marine aquaculture and aquatic products processing industry. To build a national health ecological farming demonstration area, spread healthy ecological breeding pattern and carry out construction of sea ranch, gather the high value of fishery resources.

\section{Upgrade marine traditional advantage industry and cultivate strategic emerging industry}

Some traditional industries like marine fishery, marine transportation, equipment manufacturing and coastal tourism will remain as the important pillar of marine economic development in Qinhuangdao. From the view of industry technology progress, industry associations, industry contribution, the industries of marine oil gas, marine biological medicine, marine chemical, comprehensive utilization of seawater, marine engineering equipment manufacturing, marine renewable energy and marine monitoring services have characters of long industry chain ,high correlation degree,strong radial force and powerful driving force.These should be treated asstrategic industries related to the future of marine economy in Qinhuangdao and even the development of coastal areas in Hebei province.

\section{Protection and restoration of the coastline and key sea area resources and environment}

The combination of marine economic growth mode transformation, marine industry and the spatial layout optimization of ocean industrial, the combination of terrestrial pollution control, river pollution control, polluted water management of "hardest-hit areas"and ecological restoration, will promote the synchronous development of marine economy and marine environmental protection, 
strengthen the infrastructure assurance of the sustainable development of marine economy's resources and environmental.

\section{Summary}

By 2015, Qinhuangdao will be a city with powerful marine economic, reasonable structure optimization, prominent radiation and service function, good marine ecological environment ,perfect system of science and education culture, flexible systems and mechanisms, will play a leading role in the Bohai economic development. By 2020, Qinhuangdao will preliminary build an ecological marine economy demonstration area, form a batch of marine economy enterprise brand and industry brand with high popularity, influential and strong competitiveness both at home and abroad, make the marine economy as the city brand, strive to become a powerful marine economy city in "the new east".

\section{Acknowledgement}

Fund Project: This article is a project of social science development research in Hebei province in 2014,Research title:Modern social organization system construction of the social management innovation in hebei province.

\section{References}

[1] Wang Jianyou. Zhoushan marine development path of evolution, path dependence and strategic outlook[J].Ocean Development and Management, 2010,(5):99

[2] Du Liqiang. The protection and sustainable utilization of Marine biological resources in Qinhuangdao[J].Anhui Agricultural Sciences,2012,(22):745

[3] Wang Jianyou. Zhoushan marine development path of evolution, path dependence and strategic outlook[J].Ocean Development and Management, 2010,(5):99

[4] The file assembly Qinhuangdao the Twelfth Five-Year Plan for national economic and social development (below)[M].Development and Reform Commission of Qinhuangdao,2012:464 